\title{
Meta-analisis of the etiology of odontogenic maxillary sinusitis
}

\author{
Oscar Arias-Irimia ${ }^{1}$, Cristina Barona-Dorado ${ }^{2}$, Juan A. Santos-Marino ${ }^{1}$, Natalia Martínez-Rodríguez ${ }^{3}$, \\ José $M^{a}$ Martínez-González ${ }^{4}$
}

\author{
${ }^{1}$ Oral Surgeon of the Oral and Implantological Surgery Department of the Hospital de Madrid \\ ${ }^{2}$ Associate Professor of Surgery of Madrid Complutense University. Subdirector of the Master of Oral Surgery and Implantology \\ of the Hospital de Madrid \\ ${ }^{3}$ Assistant of the Oral and Implantological Surgery Department of the Madrid Hospital \\ ${ }^{4}$ Assistant Professor of Surgery of Madrid Complutense University. Chairman of the Oral and Implantological Surgery De- \\ partment of the Hospital de Madrid
}

Correspondence:

C/ Jumilla, 27

Las Rozas 28230 (Madrid)

dentoscar@hotmail.com

Received: 15/02/2009

Accepted: 30/07/2009
Arias-Irimia O, Barona-Dorado C, Santos-Marino JA, Martínez-Rodriguez N, Martínez-González JM. Meta-analsis of the etiology of odontogenic maxillary sinusitis. Med Oral Patol Oral Cir Bucal. 2010 Jan 1;15 (1):e70-3.

http://www.medicinaoral.com/medoralfree01/v15i1/medoralv15ilp70.pdf

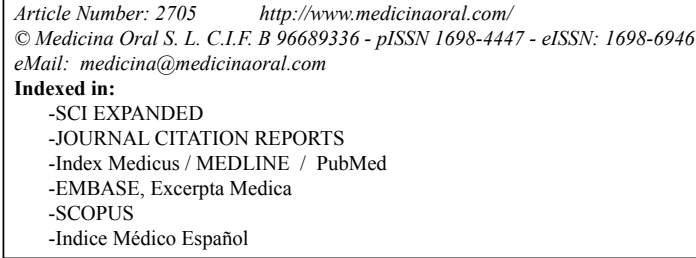

\begin{abstract}
Objective: To identify and evaluate the frequency of the different odontogenic conditions that may lead to maxillary sinusitis. Study design: An observational and retrospective meta-analysis was carried out on 770 cases of maxillary sinusitis obtained from a literature review of 15 articles. Results: Maxillary sinusitis most commonly manifests itself as chronic maxillary sinusitis. It is more common in females and is most often diagnosed in the fifth decade of life. The teeth most predominantly affected are the molars, with the first molar tooth being the most frequently involved. The principal etiological factor is extraction.
\end{abstract}

Key words: Maxillary sinusitis, iatrogenia, maxillary sinus, periodontitis.

\section{Introduction}

The inflammation of the sinus membrane that covers the paranasal sinus is refered as "maxillary sinusitis". Among the four pair of paranasal sinus, the maxillary sinus are the biggest ones and those most frequently damaged. Possible etiologies comprise local and systemic conditions which can be subdivided into acute, subacute and chronic forms according to their evolution. Whereas the first two are usually produced by infections or allergic rhinogenous sources, the chronic form is usually associated with an odontogenic origin.

Normally the roots of the maxillary premolar and molar teeth are separated from the sinus floor by a dense cortical bone with a variable thickness, but sometimes they are separated only by the mucoperiosteum. Clearly, this anatomical layout can explain the source and development of an inflammatory process, and it is this close relationship the responsible for the $37-40,6 \%$ (1) odontogenic origin of the maxillary sinusitis for many authors.

The high incidence of this pathology reveals the need to recognize it as an important disease we have to be able to deal with in order to prevent it or even treat it whenever necessary. 


\section{Material and Methods}

Study design: An observational and retrospective metaanalysis was made of the results obtained from a PubMed literature search, 41 articles published between 1986 and 2007. Among them, only 15 articles were chosen (Table 1) after applying the inclusion criteria selected: exhibit at least ten cases of maxillary sinusitis of odontogenic origin on which their etiological agent was included.

A total of 770 cases were registered from these 15 articles which were subjected to descriptive statistical analysis, with evaluation of the following parameters: Age: The age of each patient at the time of the diagnosis was registered as well as the average age and that splitted into intervals.

Gender: The patient gender was recorded and analyzed to determine whether maxillary sinusitis had a predilection for one gender or the other.

Tooth involved: We assessed the different teeth involved

Table 1. Etiological factors

\begin{tabular}{|l|c|c|}
\hline \multicolumn{1}{|c|}{ Author } & Etiological factor & $\begin{array}{c}\text { Number } \\
\text { of cases }\end{array}$ \\
\hline \multirow{3}{*}{ Brook I.(2) } & Acute pulpitis & 7 \\
\cline { 2 - 3 } & Periodontal disease & 10 \\
\cline { 2 - 3 } & Iatrogenia & 29 \\
\cline { 2 - 3 } & Radicular cyst & 2 \\
\hline \multirow{2}{*}{ Costa F.(3) } & Periimplantitis & 2 \\
\cline { 2 - 3 } & Iatrogenia & 8 \\
\hline Legent et al.(4) & Odontogenic cyst & 7 \\
\hline Selmani et al.(5) & Iatrogenia & 68 \\
\hline Ugincius et al.(6) & Iatrogenia & 13 \\
\hline \multirow{2}{*}{ Melen et al.(1) } & Periodontal disease & 82 \\
\cline { 2 - 3 } & Iatrogenia & 17 \\
\hline \multirow{2}{*}{ Lopatin et al.(7) } & Iatrogenia & 60 \\
\cline { 2 - 3 } & Odontogenic cyst & 10 \\
\hline \multirow{2}{*}{ Nishimura \& Iizuka.(8) } & Periodontal disease & 73 \\
\cline { 2 - 3 } & Iatrogenia & 7 \\
\hline \multirow{2}{*}{ Nimigean V.R. et al.(9) } & Periodontal disease & 99 \\
\cline { 2 - 3 } & Iatrogenia & 26 \\
\hline Abrahams \& Glass- & Periodontal disease & 32 \\
\hline Nishimura T.(11) & Periodontal disease & 15 \\
\hline Thevoz et al(12) & Iatrogenia & 10 \\
\hline Fligny et al.(13) & Iatrogenia & 11 \\
\hline Racic et al.(14) & Iatrogenia & 32 \\
\hline Doud Galli et al.(15) & Iatrogenia & 14 \\
\hline
\end{tabular}

in this disease in order to evaluate the frequency with which they caused maxillary sinusitis.

Type of sinusitis: We analyzed the frequency of each type of maxillary sinusitis: acute, subacute and chronic.

Etiological origin: The etiological agent responsible for the onset of this disease was recorded and analyzed so as to establish its frequency.

\section{Results}

Regarding the age, the mean patient age at the time of the diagnosis of maxillary sinusitis was found to be 42,7 years (ranged 16-80 years) being the fourth decade the most frequently affected.

Concerning the analysis of the patient gender, it was more prevalent in women $(57,7 \%)$ versus men $(42,82 \%)$ with a ratio $1 / 1,33$.

About the main antral tooth involved, the molar region standed out with a maxillary sinusitis frequency of $47,68 \%$. The first molar tooth was the most frequently affected with an incidence of $22,51 \%$, followed by the third molar tooth $(17,21 \%)$ and the second molar tooth (3,97\%). Regarding the premolar region, it was only affected in 5,96\% of the cases, being the second premolar tooth the most frequently involved $(1,98 \%)$. On the other hand, the canine only participated in $0,66 \%$ of the cases of maxillary sinusitis (Fig. 1).

Bilateral cases are rare. However, in this study, we found $2 \%$ more cases on the left maxillary sinus compared to the right one.

In relation to the etiological agent, the iatrogenia was by far, the most frequent cause of this disease $(55,97 \%)$. Other possible etiologies included: the periodontitis $(40,38 \%)$ and the odontogenic cysts $(6,66 \%)$. Beyond iatrogenia there were several factors which led to developing maxillary sinusitis. Oroantral fistules and the remaining roots, taken together as iatrogenia after tooth extraction, accounted for $47,56 \%$ within iatrogenic causes where as the dressings to close these oroantral fistules and the nonspecific foreign bodies for the $19,72 \%$.

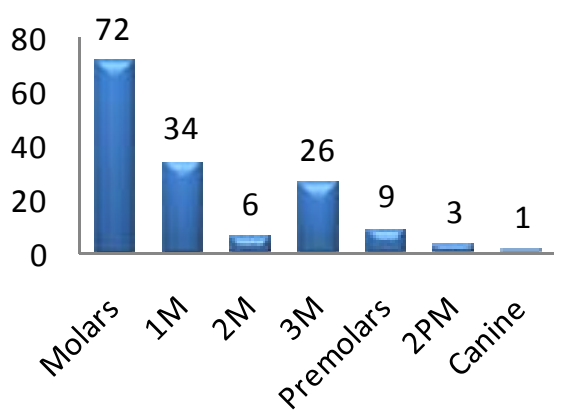

Fig. 1. Tooth involved. 
The extrusion of endodontic obturation materials into the maxillary sinus represented the $22,27 \%$, the amalgam remains after apicoectomies the 5,33\%, the maxillary sinus lift preimplantology surgery the $4,17 \%$, and poorly positioned dental implants or those migrated to the maxillary sinus the $0,92 \%$ of all cases included under a iatrogenic source.

\section{Discussion}

Maxillary sinusitis is a disease that often involves odontologists, both in its diagnosis and its prevention. As we have reported with our results, iatrogenia is its main cause. However, despite its high prevalence, there is very little literature among odontologists, which contrasts with the fact that $90 \%$ of the reviews that are interested on this disease come from the field of the otorhinolaryngologists.

In this study, iatrogenia is much more frequent than other etiological factors such as chronic periodontitis, which has been considered by many authors as the most common way of spreading oral pathogens to the maxillary sinus. This disagreement with our results, as discussed by Hugoson et al. (16) may be possibly attributed to a decrease in chronic periodontitis due to a better oral hygiene.

However beyond the term iatrogenia there is a wide range of factors which can be taken into account. It is by all known that one of the most frequent activities done in a dental office are teeth extractions; if we are aware of the close relationship between the antral tooth and the maxillary sinus and of the fact that oroantral fistules can be considered as a complication after tooth extraction, it is fairly reasonable to believe (and in that way it has been shown in this study), that postextraction iatrogenic sinusitis accounts for the highest percentage of published cases. In addition, it can also be revealed how the prognosis is markedly worsed by the foreign body reaction caused after many attempts of correcting the bucosinusal communications with postextraction dressings and by unremoved foreign bodies.

Another activity prone to develop iatrogenia is the increasing demand of implantological treatments we are dealing nowadays, specially by patients with persistent edentulism in the subantral regions whose rehabilitation complicates the technique since they require sinus floor elevation. These techniques of sinus lift with bone grafts were initially described in the 70 's decade. Their aim was to sort out the anatomical limitations which accounted during the placement of implants in the edentulous near maxillary bone. There have been several reports that associate the floor sinus elevation with the development of sinusitis such as the one described by Raghoebar et al. (17) in which the sinus membrane was drilled in 45 patients with only two of them suffering from sinusitis. The implants placement can also produce sinusitis although for many authors, this is very rare. Adell et al.
(18) observed no sinusal complications in 101 implants introduced between 2 to $4 \mathrm{~mm}$ in the sinus after 10 years follow up illustrating that complications associated with implants which emerge the maxillary sinus are not higher than those which do not break through it.

As regards apicoectomies, it seems obvious that its close relationship with the sinus floor makes it more difficult to achieve good results without complications. Nevertheless, they entail a complication less frequent than expected, since the vast majority of the professionals prior tooth extraction to this technique, as there is a high risk of accidental exposure of the sinus because of the close relationship between this one and the apex. Even so, reports such as the one published by Freedman et al. (19) in which after 472 apicoectomies, there were $23 \%$ of drilled molars, $13 \%$ of drilled second premolars and $2 \%$ of drilled first molars without developing sinusitis any of them, reveal that there is no contradiction in making apicoectomy over antral teeth, despite its proximity to the maxillary sinus (20). On the other hand, a foreign body reaction may develop if amalgam remains are left on the bone cavity prepared for apicoectomy.

In the endodontic field, it is the extrusion of any of the materials used in the procedure the responsible for the inflammation of the surrounding tissues, including the antral mucosa. Therefore, not making a correct apical stop whenever doing a root canal therapy on an antral tooth, has a high risk of producing maxillary sinusitis. Periodontal disease as an etiological agent of sinusitis has been reported long ago, for example Bauer in 1943 demonstrated after studies done on corpses, the direct dissemination of a bucal sepsis to the maxillary sinus. More recently, Abrahams et al. (10) have observed that sinusitis incidence on patients with periodontal disease is double to that on patients without periodontal disease. The relationship between the inflammation of the periapical tissues and the damage to the sinus membrane ended up in the known syndrome of "Endo-antral syndrome". However, in the last few years, the incidence of this purpose has decreased probably in relation to many factors already discussed, pointing out the improvement of oral hygiene and the preventive techniques concerning the periodontal disease. This improvement of oral hygiene is of outstanding relevance since the current conservative trend leads in many times to preserve teeth with periodontal disease as they have a slow and chronic evolution inducing symptoms only after years of illness.

The low incidence of sinusitis concerning cysts is mainly due to the fact that during their development, they push the sinus structures causing them no damage unless an infection accounts or the ostium obstructs preventing the natural drainage of the sinus. In either situation as in the cases published by Costa (3) or Lopatin et al. (7) a maxillary sinusitis will develop, however it is still a rare etiology. 


\section{References}

1. Melén I, Lindahl L, Andréasson L, Rundcrantz H. Chronic maxillary sinusitis. Definition, diagnosis and relation to dental infections and nasal polyposis. Acta Otolaryngol. 1986;101:320-7.

2. Brook I. Microbiology of acute and chronic maxillary sinusitis associated with an odontogenic origin. Laryngoscope. 2005;115:823-5. 3. Costa F, Emanuelli E, Robiony M, Zerman N, Polini F, Politi M. Endoscopic surgical treatment of chronic maxillary sinusitis of dental origin. J Oral Maxillofac Surg. 2007;65:223-8.

4. Legent F, Billet J, Beauvillain C, Bonnet J, Miegeville M. The role of dental canal fillings in the development of Aspergillus sinusitis. A report of 85 cases. Arch Otorhinolaryngol. 1989;246:318-20.

5. Selmani Z, Ashammakhi N. Surgical treatment of amalgam fillings causing iatrogenic sinusitis. J Craniofac Surg. 2006;17:363-5.

6. Ugincius P, Kubilius R, Gervickas A, Vaitkus S. Chronic odontogenic maxillary sinusitis. Stomatologija. 2006;8:44-8.

7. Lopatin AS, Sysolyatin SP, Sysolyatin PG, Melnikov MN. Chronic maxillary sinusitis of dental origin: is external surgical approach mandatory? Laryngoscope. 2002;112:1056-9.

8. Nishimura T, Iizuka T. Evaluation of the pathophysiology of odontogenic maxillary sinusitis using bone scintigraphy. Int J Oral Maxillofac Surg. 2002;31:389-96.

9. Nimigean VR, Nimigean V, Maru N, Andressakis D, Balatsouras DG, Danielidis V. The maxillary sinus and its endodontic implications: clinical study and review. B-ENT. 2006;2:167-75.

10. Abrahams JJ, Glassberg RM. Dental disease: a frequently unrecognized cause of maxillary sinus abnormalities?. AJR Am J Roentgenol. 1996;166:1219-23.
11. Nishimura T, Iizuka T. Evaluation of odontogenic maxillary sinusitis after conservative therapy using $\mathrm{CT}$ and bone SPECT. Clin Imaging. 2002;26:153-60.

12. Thévoz F, Arza A, Jaques B. Dental foreign body sinusitis. Schweiz Med Wochenschr. 2000;Suppl 125:30S-34S.

13. Fligny I, Lamas G, Rouhani F, Soudant J. Chronic maxillary sinusitis of dental origin and nasosinusal aspergillosis. How to manage intrasinusal foreign bodies?. Ann Otolaryngol Chir Cervicofac. 1991;108:465-8.

14. Racić A, Dotlić J, Janosević L. Oral surgery as risk factor of odontogenic maxillary sinusitis. Srp Arh Celok Lek. 2006;134:191-4.

15. Doud Galli SK, Lebowitz RA, Giacchi RJ, Glickman R, Jacobs JB. Chronic sinusitis complicating sinus lift surgery. Am J Rhinol. 2001;15:181-6.

16. Hugoson A, Norderyd O, Slotte C, Thorstensson H. Distribution of periodontal disease in a Swedish adult population 1973, 1983 and 1993. J Clin Periodontol. 1998;25:542-8.

17. Raghoebar GM, Van Weissenbruch R, Vissink A. Rhino-sinusitis related to endosseous implants extending into the nasal cavity. A case report. Int J Oral Maxillofac Surg. 2004;33:312-4.

18. Adell R, Lekholm U, Rockler B, Brånemark PI. A 15-year study of osseointegrated implants in the treatment of the edentulous jaw. Int J Oral Surg. 1981;10:387-416.

19. Freedman A, Horowitz I. Complications after apicoectomy in maxillary premolar and molar teeth. Int J Oral Maxillofac Surg. 1999;28:192-4.

20. García B, Martorell L, Martí E, Peñarrocha M. Periapical surgery of maxillary posterior teeth. A review of the literature. Med Oral Patol Oral Cir Bucal. 2006;11:E146-50. 